\title{
Effects of DIDS on the Chick Retinal Pigment Epithelium. I. Membrane Potentials, Apparent Resistances, and Mechanisms
}

\author{
Ron P. Gallemore and Roy H. Steinberg \\ Departments of Physiology and Ophthalmology, University of California, San Francisco, San Francisco, California 94143
}

While little is known about the transport properties of the retinal pigment epithelium (RPE) basal membrane, mechanisms for anion movement across the basal membrane appear to be present (Miller and Steinberg, 1977; Hughes et al., 1984; Miller and Farber, 1984). This work examines the electrophysiological effects of the anion conductance blocker, 4,4'-diisothiocyanostilbene-2,2' -disulfonate (DIDS) on the basal membrane of an in vitro preparation of chick retinaRPE-choroid. DIDS (10-125 $\mu \mathrm{M}$ ), added to the choroidal bath, decreased the transtissue potential by decreasing the potential across the RPE. Intracellular RPE recordings showed that DIDS affected the membrane potential in 2 phases, initially hyperpolarizing the basal membrane and then, after prolonged exposure, depolarizing the apical membrane. Resistance assessment by transtissue current pulses and intracellular c-wave recordings suggested that DIDS increased basal membrane resistance $\left(\boldsymbol{R}_{\mathrm{ba}}\right)$ during the first phase and increased apical membrane resistance $\left(R_{\mathrm{ap}}\right)$ during the second phase. Measurements of intracellular $\mathrm{Cl}^{-}$activity $\left(a_{\mathrm{cl}}\right)$ showed that $\mathrm{Cl}^{-}$was actively accumulated by the chick RPE since it was distributed above equilibrium across both the apical and basal membranes. Perfusion of the basal membrane with $50 \mu \mathrm{M}$ DIDS significantly increased $a_{\mathrm{cl}-\text { - }}$ The DIDSinduced basal membrane hyperpolarization, apparent increase in $\boldsymbol{R}_{\mathrm{ba}}$, and increase in $\mathrm{a}_{\mathrm{cl}}^{\mathrm{i}}$ are all consistent with $\mathrm{Cl}^{-}$-conductance blockade. During the second phase, apical membrane responsiveness to the light-evoked decrease in subretinal $\left[\mathrm{K}^{+}\right]_{0}$ (Oakley, 1977) was reduced an average of $58 \%$. This finding, given the second-phase apical membrane depolarization and apparent increase in $R_{\mathrm{ap}}$, is consistent with a decrease in apical membrane $K+$ conductance. This work suggests that one effect of DIDS is to block a basal membrane $\mathrm{Cl}^{-}$conductance, while with prolonged exposure there is a secondary effect on the apical membrane, which may represent a decrease in $K^{+}$conductance.

\footnotetext{
Received July 15, 1988; revised Oct. 12, 1988; accepted Nov. 4, 1988.

We thank Drs. Chris Berry and Floyd Rector for helpful discussions, Dr. Gregory Fitz for suggestions on $\mathrm{Cl}^{-}$electrode construction, Dr. Nobu Nao-i for participation in some experiments, and Dr. Bret Hughes for helpful discussions and for his critical reading of the manuscript.

Supported by NIH Grant No. EY01429 (R.H.S.) and, in part, by a Fight for Sight Student Fellowship (R.P.G.), a Retinitis Pigmentosa Foundation Student Fellowship (R.P.G.), and a University of California, Irvine, Dean of Biological Sciences Research Scholarship (R.P.G.).

Correspondence should be addressed to Dr. Roy H. Steinberg, Department of Physiology, S-762, University of California, San Francisco, CA 94143-0444.
}

Copyright $(\mathcal{C} 1989$ Society for Neuroscience $0270-6474 / 89 / 061968-09 \$ 02.00 / 0$
The retinal pigment epithelium (RPE) regulates the transport of metabolites between the photoreceptors and their choroidal blood supply. In response to illumination, communication occurs between the photoreceptors and the RPE that can be recorded in the DC electroretinogram (DC ERG) in the form of 3 components: the $c$-wave, the fast-oscillation trough, and the light peak (light-rise of the electrooculogram; Steinberg et al., 1985). The c-wave component originates at the RPE apical membrane as a voltage response to the light-evoked decrease in potassium in the subretinal space (Oakley and Green, 1976; Oakley, 1977; Steinberg et al., 1980) and is mediated by the presence of a barium-blockable potassium conductance (Griff et al., 1985). Both the fast-oscillation trough, and the light peak originate as changes in the potential of the basal membrane, but the mechanisms that cause these events remain unknown. In fact, little is known about the ionic conductances and transporters that contribute to the basal membrane potential in species that have these responses, i.e., reptiles, birds and mammals (Kikawada, 1968).

The RPE of frog, an amphibian, has been shown to transport anions actively from the apical side to the basal side (Hughes et al., 1984; Miller and Farber, 1984), indicating that mechanisms for anion movement must be present in the basal membrane. To investigate the significance of such anion movement in a preparation that has the 2 basal membrane light-dependent responses, we perfused the chick basal membrane with the anion transport and conductance blocker, 4,4' -diisothiocyanostilbene2,2'-disulfonate (DIDS; e.g., Miller and White, 1979; Jentsch et al., 1986). We studied the effects of DIDS on the electrical properties of the RPE using intracellular recordings of membrane potentials, the membrane resistance ratio ( $a$ value), and RPE c-wave membrane hyperpolarizations. In addition, using double-barreled $\mathrm{Cl}^{-}$-selective microelectrodes, we measured intracellular $\mathrm{Cl}^{-}$- activity.

This paper presents the effects of DIDS on electrical parameters of the RPE and neural retina and considers the potential mechanisms underlying these effects. The following paper (Gallemore and Steinberg, 1989) describes the effects of DIDS on responses originating at the RPE basal membrane-the light peak of the DC electroretinogram, the azide response (Linsenmeier and Steinberg, 1987), and the effects of a retinal hyperosmotic load (Shirao and Steinberg, 1987)-and addresses how these effects may be related to the mechanisms underlying these responses. Preliminary results of parts of this work have appeared in abstract form (Gallemore and Steinberg, 1987, 1988).

\section{Materials and Methods}

Preparation and solutions. White chicks (Gallus domesticus), 1-14 d old, were first light-adapted for at least $2 \mathrm{hr}$ to promote adhesion of the 
neural retina to the RPE. They were then dark-adapted for 10 min prior to decapitation to reduce the chance of spreading depression (see below). The eye was enucleated and mounted, cornea down, in a dissecting chamber filled with a control perfusate (solutes in mM: $120.0 \mathrm{NaCl}, 25.0$ $\mathrm{NaHCO}_{3}, 25.0$ dextrose, $5.0 \mathrm{KCl}, 3.0 \mathrm{MgCl}_{2}, 1.8 \mathrm{CaCl}_{2}$ ), which was constantly oxygenated with $95 \% \mathrm{O}_{2} / 5 \% \mathrm{CO}_{2}$ gas, $\mathrm{pH} 7.5 \pm 0.1$, at 36.0 $\pm 1.0^{\circ} \mathrm{C}$. The osmolarity of this solution was $308 \pm 6 \mathrm{mOsm}$ (Advanced WideRangeOsmometer 3 W2, AdvancedInstruments, Needham Heights, MA). An incision was made through the sclera, with carc taken not to penetrate the choroid, and the sclera posterior to the ora serrata was dissected from the choroid. A 2-5 $\mathrm{mm}$ incision was made through the choroid, RPE, and retina, and a circular portion of retina-RPE-choroid tissue, $4-8 \mathrm{~mm}$ in diameter, was excised and placed, choroidal surface down, over a $3 \mathrm{~mm}$ hole in the center of a thin plastic film. The plastic film and the tissue were then mounted between 2 Lucite plates in a perfusion chamber as previously described for other preparations (Miller and Steinberg, 1977; Griff and Steinberg, 1982). The choroidal and retinal surfaces of the tissue were separately perfused such that substances added to the choroidal solution encounter the basal surface of the RPE after diffusion through the choroid, while substances added to the retinal perfusate encounter the apical surface after diffusion through the neural retina. The perfusion system was identical to those previously described except that to maintain the temperaturc of the perfusate at $36.0 \pm 1.0^{\circ} \mathrm{C}$, heater coils were inserted before the retinal and choroidal inlets of the perfusing chamber and all solutions were preheated.

The anion transport and conductance blockers DIDS and 4-acetamido- 4 '-isothiocyanostilbene (SITS) were added to the choroidal perfusate in the following concentrations $(\mu \mathrm{M}): 10.0$ (DIDS only), 35.0, 50.0, 100.0, and 125.0. Care was taken to minimize exposure to white light since DIDS and SITS are light sensitive (Sigma, packing instructions).

Chick retinas are prone to spreading depression - a condition readily produced by tissue damage, low temperature, and light (Martins-Ferreira and Oliveira Castro, 1971). We reduced the frequency of spreading depression by careful dissection technique, by temperature control, by dark-adapting for $10 \mathrm{~min}$ following the initial period of light adaptation, and by elevating $\mathrm{Mg}^{2+}$ to $3.0 \mathrm{~mm}$ [3 times the concentration used in similar preparations of frog (Miller and Steinberg, 1977) and lizard (Griff and Steinberg, 1982)]. Because of this relatively high $\mathrm{Mg}^{2+}$ concentration in the control perfusate, synaptic transmission in the neural retina was normally suspended to some degree as evidenced by the small b-wave in the DC ERG (Gallemore et al., 1988).

Stimuli. Prior to the start of recording, the tissue was dark-adapted for approximately $1 \mathrm{hr}$. A halogen lamp was used to deliver a diffuse white light stimulus through a mirror, a neutral density filter and a pair of condenser lenses for a final stimulus intensity of $6 \times 10^{-5} \mathrm{~W} / \mathrm{cm}^{2}$. To elicit a c-wave or light peak, a $4 \mathrm{sec}$ or $300 \mathrm{sec}$ stimulus was presented at an interval of 60-90 sec or 45-60 min, respectively.

Electrodes. Conventional microelectrodes were made from $1.0 \mathrm{~mm}$ glass tubing (Omega Dot Glass Co. of America, Millville, NJ) with a horizontal electrode puller (model p-77, Sutter Instruments Co., San Francisco), filled with $5.0 \mathrm{M}$ potassium acetate, and bevclcd to a resistance of either $80-100 \mathrm{M} \Omega$ for intracellular recordings or 5-10 M $\Omega$ for extracellular recordings (model BV-10, Sutter Instruments Co.). Unitygain amplifiers (model 1090, Winston Electronics, San Francisco) with input resistances of $10^{14} \Omega$, were used to measure microelectrode potentials.

Potassium- and chloride-selective microelectrodes were constructed from double-barreled glass tubing (Omega Dot Glass Co. of America), using a modification of the technique described by Djamgoz and Dawson (1986). Double-barreled glass, first broken to offset the ends of the 2 barrels, was washed in aqua regia ( 1 part concentrated $\mathrm{HCl}: 3$ parts concentrated $\mathrm{HNO}_{3}, \mathrm{vol} / \mathrm{vol}$ ), and rinsed thoroughly in distilled water. The glass was then dried $\left(150^{\circ} \mathrm{C}\right)$ and desiccated. Microelectrodes were pulled on the horizontal puller described above. The longer barrel was silanized for $15-45 \mathrm{sec}$ by lowering it through a hole in the cap of a glass jar containing about $1 \mathrm{ml}$ of dimethyl-dichloro-silane (Sigma). The reference barrel (shorter barrel) was plugged with dental wax to prevent silanization. The tip of the active barrel (longer barrel) was then filled with $\mathrm{K}^{+}$liquid ion-exchange resin (Corning \#477317) or $\mathrm{Cl}^{-}$liquid ionexchange resin (Corning \#477913) and back-filled with 500 or $150 \mathrm{mM}$ $\mathrm{KCl}$. The reference barrel was back-filled with $5 \mathrm{M} \mathrm{LiCl}\left(\mathrm{K}^{+}\right.$-selective microelectrodes) or $5 \mathrm{M}$ Kacetate $\left(\mathrm{Cl}^{-}\right.$-selective microelectrodes). The tips of the $\mathrm{K}^{+}$-selective microelectrodes were broken to $1-3 \mu \mathrm{m}$ by dragging the tip across the Kimwipe paper tissue. Chloride-selective microelectrodes were used without beveling and had reference barrel

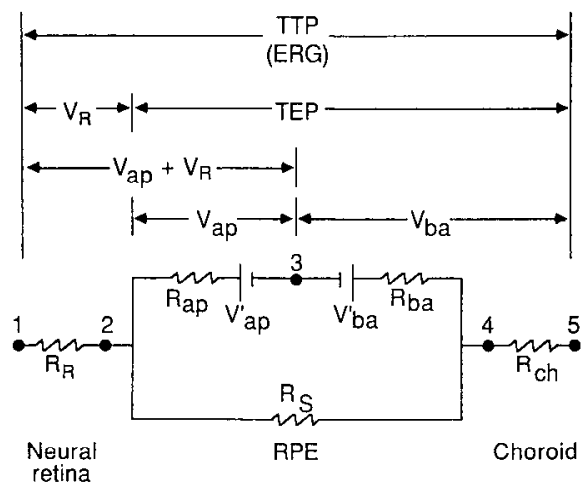

Figure 1. Equilalent circuit for the chick neural retina-RPE-choroid preparation. The neural retina and choroid are represented by the resistors $R_{R}$ and $R_{\mathrm{ch}}$, respectively. For the RPE, the apical, membrane is represented by a resistor, $R_{\mathrm{ap}}$, in series with a battery, $V_{a p}^{\prime}$. Similarly, the basal membrane is represented by a resistor, $R_{\mathrm{ba}}$, and a battery, $V_{\mathrm{ba}}^{\prime}$. The membrane resistances are shunted by a resistor, $R_{v}$, the paracellular pathways. As a result of current flow across $R_{\mathrm{ap}}$ and $R_{\mathrm{ba}}$, the membrane potentials recorded across these resistances ( $V_{\mathrm{ap}}$ and $V_{\mathrm{ba}}$, respectively) differ from the membrane batteries $\left(V_{\mathrm{ap}}^{\prime}\right.$ and $\left.V_{\mathrm{ba}}^{\prime}\right)$. The standing potential across the RPE-choroid is the transepithelial potential $(T E P)$, and the potential across the neural retina is the transretinal potential $\left(V_{R}\right)$. The transtissue potential $(T T P)$ is the sum of TEP and $V_{R}$. The change in TTP in response to light is the DC electroretinogram (DC ERG). Extracellular electrodes were placed in the retinal perfusate (position 1 ) and the choroidal perfusatc (position 5). The microclectrode was placed either in the subretinal space (position 2), intracellularly in the RPE (position 3), or in the subchoroidal space (position 4).

resistances between 60 and $100 \mathrm{M} \Omega$. Elcctrodes were connected to a high-input-impedance electrometer (WPI model F23) and calibrated before and after each experiment. Details of the calibration procedures used for each type of electrode are presented below.

Potassium-selective microelectrodes were routinely calibrated at room temperature before and after each experiment by measuring their response to a decade change in $\left[\mathrm{K}^{+}\right]$: from $1 \mathrm{mM} \mathrm{KCl}, 111 \mathrm{mM} \mathrm{NaCl}$ to $10 \mathrm{~mm} \mathrm{KCl}, 102 \mathrm{~mm} \mathrm{NaCl}$. The mean response of acceptable electrodes was $39 \mathrm{mV}$ ( $n=20$ electrodes), similar to that reported previously (Linsenmeier and Steinberg, 1984). This is less than ideal Nernstian behavior because $\mathrm{Na}^{+}$interference is most noticeable at low $\mathrm{K}^{+}$concentrations. $\mathrm{K}^{+}$electrodes were stable for about a week after construction.

Chloride-selective microelectrodes were calibrated in a series of solutions including $10,25,100$, and $150 \mathrm{mM} \mathrm{KCl}$ (madc isoosmotic with mannitol) at room temperature. The slope of the electrode response was determined from the regression line of voltage against the logarithm of chloride concentration $\left(\left[\mathrm{Cl}^{-}\right]\right)$. The slope of the electrodes used in this study averaged $55.6 \pm 1.2 \mathrm{mV}$ per 10 -fold change in $\left[\mathrm{Cl}^{-}\right]$with a response time to $90 \%$ of the final value within $5 \sec (n=9$ electrodes). These slopes are similar to those reported by others (Baumgarten, 1981; Saito et al., 1987). The mean active barrel resistance for these electrodes was $53 \times 10^{9} \Omega$ (range, $20 \times 10^{9}$ to $130 \times 10^{9} \Omega$ ). The selectivity coefficient, $k_{\mathrm{HCO}_{3} / \mathrm{Cl}}$, of the chloride electrodes for bicarbonate $\left(\mathrm{HCO}_{3}^{-}\right)$, a major interfering ion that may affect the determination of intracellular chloride activity (Armstrong and Garcia-Diaz, 1980; Baumgarten, 1981), was determined by comparing the voltage observed in $25 \mathrm{~mm} \mathrm{KCl}$ to that in $25 \mathrm{mM} \mathrm{KHCO}_{3}$ (bubbled with $95 \% \mathrm{O}_{2} / 5 \% \mathrm{CO}_{2}$ ). The average value for $k_{\mathrm{HCO}_{3} / \mathrm{Cl}}$ was 0.083 , corresponding to a mcan $\mathrm{Cl}^{-} / \mathrm{HCO}_{3}{ }^{-}$selectivity of 1:12 (range, 1:10-20).

Intracellular chloride activity $\left(a_{\mathrm{C}}^{\mathrm{i}}\right)$ was determined from the relationship (for references see Armstrong and Garcia-Diaz, 1980):

$$
a_{\mathrm{Cl}}^{\mathrm{i}}=10^{\left(\mathrm{V}_{\mathrm{Cl}} / S\right)}\left[a_{\mathrm{O}}^{\circ}+\left(k_{\mathrm{HCO}_{3} / \mathrm{Cl}} a_{\mathrm{HCO}_{3}}^{\circ}\right)\right]
$$

where $V^{\mathrm{Cl}}$ is the differential voltage between the ion-selective and reference barrels, $S$ is the calibration slope of the electrode, and $a^{\circ}$ and $a^{\circ}{ }_{\mathrm{HrO}_{3}}$ are the extracellular $\mathrm{Cl}^{-}$and $\mathrm{HCO}_{3}{ }^{-}$activities, respectively, calculated from concentration assuming a $\mathrm{Cl}^{-}$and $\mathrm{HCO}_{3}^{-}$activity coefficient of 0.75 (Koryta and Stulik, 1983). The $a_{C l}^{i}$ predicted for passive 
distribution across each membrane was calculated using the Nernst equation and assuming that the extracellular $\mathrm{Cl}^{-}$activity was equal to that in the bulk solution:

$$
a_{\mathrm{Cl}}^{\mathrm{i}}(\text { passive })=10^{\left(\mathrm{V}^{\prime} / 61 \mathrm{mV}\right)} a_{\mathrm{Cl}}^{\circ}
$$

Recording configurations and equivalent circuit. The recording configurations and equivalent circuit are schematically illustrated in Figure 1. Glass microelectrodes could be placed in the subretinal space (subretinal recording, position 2), in an RPE cell (intracellular RPE recording, position 3 ), or in the subchoroidal space (subchoroidal recording, position 4). The subretinal recording, when referenced to the choroidal electrode (position 5), yields the transepithelial potential (TEP), and the transretinal potential $\left(V_{R}\right)$ when referenced to the retinal electrode (position 1). When recording $V_{R}$ in this configuration, the subretinal space is positive and the retinal bath negative. In all illustrations, however, we have inverted the $V_{R}$ signal so that $V_{R}$, like TEP, is illustrated with the retinal bath as positive. Note that the transretinal and transepithelial resistances are shunted by the tissue edge resistance pathway (not illustrated), and, therefore, a change in TEP may produce a passive change in $V_{R}$, and vice versa. The intracellular recording gives the basal membrane potential $\left(V_{\mathrm{ba}}\right)$ when referenced to the choroidal electrode and the apical membrane potential plus transretinal potential $\left(V_{\text {ap }}+V_{R}\right)$, when referenced to the retinal electrode. Note that, unless otherwise indicated, we have assumed that changes in $\left(V_{\mathrm{ap}}+V_{R}\right)$ are representative of changes in $V_{a p}$, neglecting changes in $V_{R}$ because of their relatively small size. The potential of the retinal electrode in reference to the choroidal electrode is the transtissue potential (TTP), whose change in response to a light stimulus is defined as the DC electroretinogram.

The following equations are valid for the circuit of Figure 1, and the reader is referred to earlier publications for their derivations (Miller and Steinberg, 1977; Linsenmeier and Steinberg, 1983; Griff et al., 1985):

$$
\begin{aligned}
\Delta \mathrm{TTP} & =\Delta \mathrm{TEP}+\Delta V_{R} \\
\Delta \mathrm{TEP} & =\Delta V_{\mathrm{ba}}-\Delta V_{\mathrm{ap}} \\
\Delta V_{\mathrm{ap}} & =\Delta V^{\prime}{ }_{\mathrm{ap}} \frac{R_{\mathrm{ba}}+R_{s}}{R_{\mathrm{ap}}+R_{\mathrm{ba}}+R_{\mathrm{s}}} \\
\Delta V_{\mathrm{ba}} & =\Delta V^{\prime}{ }_{\mathrm{ap}} \frac{R_{\mathrm{ba}}}{R_{\mathrm{ap}}+R_{\mathrm{ba}}+R_{s}}
\end{aligned}
$$

where TTP is the transtissue potential; TEP, transepithelial potential; $V_{R}$, voltage across the neural retina; $V_{\mathrm{ap}}\left(V_{\mathrm{ba}}\right)$, measured potential of the apical (basal) membrane of the RPE; $V_{\mathrm{ap}}^{\prime}$, apical membrane battery; $R_{\mathrm{ap}}$ $\left(R_{\mathrm{ba}}\right)$, apical (basal) membrane resistance; $R_{s}$, paracellular shunt resistance. Equation (3) indicates that the TTP can be decreased either by a decrease in TEP, $V_{R}$, or both. The TEP represents the difference between the apical and basal membrane potentials of the RPE (Eq. 2) and, in chick, is ordinarily 8-12 $\mathrm{mV}$, subretinal space positive, with the apical membrane being more hyperpolarized than the basal. Equation (4) shows that the TEP can be decreased (increased) by a basal membrane hyperpolarization (depolarization), an apical membrane depolarization (hyperpolarization), or both. Equations (5) and (6) explain the changes in membrane potential recorded at each membrane when there is a change in an apical membrane battery, $\Delta V_{\text {ap }}^{\prime}$, as occurs during the RPE $c$-wave. Note that $\Delta V_{\text {ap }}$ is larger than $\Delta V_{\text {ba }}$, since the potential change originates at the apical membrane, but that both $\Delta V_{\mathrm{ap}}$ and $\Delta V_{\mathrm{ba}}$ are smaller than the change in the battery, $\Delta V_{\text {ap. }}^{\prime}$. Since the TEP is defined as $V_{\mathrm{ba}}-V_{\mathrm{ap}}$ (Eq. 4), the RPE c-wave (TEP c-wave) will be

$$
\Delta \mathrm{TEP}=-\left[\left(R_{s}\right) /\left(R_{\mathrm{ap}}+R_{\mathrm{ba}}+R_{s}\right)\right] \Delta V_{\mathrm{ap}}^{\prime}
$$

( $\Delta \mathrm{V}_{\text {ap }}^{\prime}$ is negative, so $\Delta$ TEP is positive.) A change in $\Delta V_{\text {ap }}^{\prime}$ and/or one or more of the resistances in Equation (7) will changc the RPE c-wave amplitude.

By applying current $(1.0 \mu \mathrm{A}, 1.0 \mathrm{sec})$ across the tissue and measuring the appropriate voltage deflections at various locations, we could determine the following resistance values: the extracellularly recorded resistances (transretinal, $R_{R}$; transepithelial, $R_{i}$; transtissue, $R_{\mathrm{tot}}$ ) and the intracellularly recorded resistance ratio (the $a$ value, $R_{\mathrm{ap}} / R_{\mathrm{ba}}$ ). The transtissue resistance, $R_{\text {of }}$ is equal to $R_{R}+R$. In our measurements, $R$, also included the resistance of the choroid, $R_{\mathrm{ch}}$. In 15 experiments, $R_{\mathrm{ch}}$ was measured with a microelectrode in the subchoroidal space referenced to the choroidal electrode and was found to be approximately $25 \%$ of
$K_{t}+R_{\mathrm{ch}}$. The ratio of $R_{\mathrm{ap}}$ to $R_{\mathrm{ba}}$ is called the $a$ value and is proportional to the voltage change (caused by the extrinsic current) across the apical and basal membranes. In calculating $a$, the retinal resistance was neglected because of its relatively small size, and the choroidal resistance was neglected because of its assumed constancy. By neglecting $R_{\mathrm{ch}}$, the actual $a$ values must be larger than those illustrated, and we are underestimating the absolute change in $a$ value. Our conclusions, however, will not be affected.

All recorded signals were displayed on both a storage oscilloscope (Tektronix 5111) and a pen recorder (Brush 220) and stored on magnetic tape (Racal 4DS). Recordings were subsequently sampled and digitized (DEC PDP $11 / 03$ ) and plotted on a digital $X-Y$ plotter (Tektronix 4662).

Statistics. Numerical results are given as means \pm SEM. Student's $t$ test was used to assess differences between paired sets of data.

\section{Results}

\section{Effect of DIDS on the transtissue potential}

When the retina-RPE-choroid preparation was perfused on its choroidal surface with $10 \mu \mathrm{M}$ DIDS, the dark-adapted TTP decreased (Fig. 2). Since the decrease in TEP had essentially the same time course and magnitude as the decrease in TTP, we concluded that the RPE rather than the neural retina was the primary site of the effect. In this example, however, and in other sets of similar recordings, a small positive going change in the transretinal potential reduced the size of the decrease in TTP. In all experiments $(n-22)$, and for all concentrations of DIDS, this change in transretinal potential was not more than $10 \%$ of the change in TEP. DIDS had a prominent effect on the TTP even at the lowest concentration used, $10 \mu \mathrm{M}$ (Fig. 2). Higher concentrations $(35-125 \mu \mathrm{M})$ produced faster and larger decreases in the TTP, while recovery times were significantly prolonged; the maximal effect of choroidal DIDS was produced with concentrations of $100 \mu \mathrm{M}$ and greater. We also used a related stilbene derivative, SITS, in concentrations of $35,50,100$, and $125 \mu \mathrm{M}$. Both SITS and DIDS had similar effects on the electrical properties of the chick RPE, decreasing the TTP, increasing tissue resistance, and decreasing the c-wave, as we will describe. Since DIDS was more potent (Gallemore and Steinberg, 1989), we limited our intracellular experiments to the use of DIDS.

Figure 3 illustrates $V_{\text {ap }}$ and $V_{\text {ba }}$ during choroidal perfusion with $50 \mu \mathrm{M}$ (Fig. $3 A$ ) and $100 \mu \mathrm{M}$ (Fig. 3B) DIDS. Although the decrease in TTP appeared to be monophasic, membrane potential changes occurred in 2 distinct phases as indicated by the vertical interrupted lines. In the first phase, during the initial $5-$ $10 \mathrm{~min}$, both membranes hyperpolarized, but the basal membrane hyperpolarization was larger and faster than the apical membrane hyperpolarization. This is consistent with choroidal DIDS hyperpolarizing the basal membrane, while the smaller apical membrane hyperpolarization is likely duc to shunting of the basal membrane potential through the paracellular resistance $\left(R_{\mathrm{s}}\right.$ in Fig. 1). In the second phase, which occurred after 5-10 min, the apical membrane depolarized. In general, this depolarization was subtle, as shown in Figure $3 A(50 \mu \mathrm{M}$ DIDS). With higher concentrations of DIDS, however, this depolarization could be quite prominent, as shown in Figure $3 B(100 \mu \mathrm{M}$ DIDS). Similar results were obtained in 5 experiments $(50 \mu \mathrm{M}$ choroidal DIDS, $n=2$, and $100 \mu \mathrm{M}$ choroidal DIDS, $n=3$ ). In summary, the data are consistent with choroidal DIDS initially hyperpolarizing the basal membrane and then, following prolonged exposure, depolarizing the apical membrane.

\section{Resistance measurements: $\mathrm{R}_{\mathrm{t}}$ and the a value}

Choroidal DIDS also caused a large and reversible increase in the transtissue resistance, $R_{\text {tot }}$ (Fig. $4 A$ ) that was due to a 12.0 
A

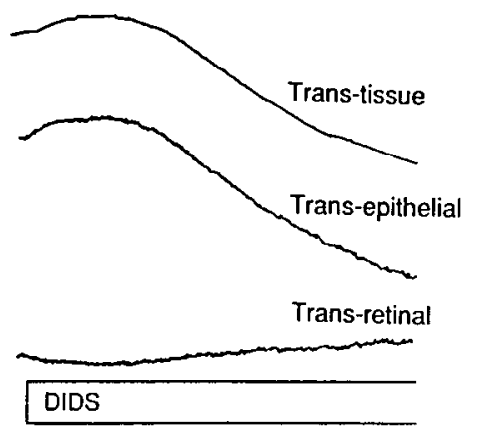

Figure 2. Effect of choroidal DIDS perfusion $(10 \mu \mathrm{M})$ on the TTP and its transepithelial and transretinal components. In $A$, the perfusate was changed to the test solution containing DIDS as indicated at the bottom by the bar. The recovery of the TTP in $B$ occurred 40 min after return to normal Ringer from the DIDS solution.

$\pm 1.6 \%(n=7)$ increase in the RPE resistance $\left(R_{t}\right.$, or more precisely, $R_{t}+R_{\mathrm{ch}}$ ) and not to an increase in retinal resistance $\left(R_{R}\right)$. Since $R_{\mathrm{ch}}$ is approximalely $25 \%$ of $R_{t}+R_{\mathrm{ch}}$, the change in $R_{i}$ itself was quite large, about $16 \%$. Note that the $50 \%$ decrease in $R_{R}$ in this experiment was unusually large, compared with the average of $18.5 \pm 3.5 \%(n=7)$.

The DIDS-induced increase in $R_{t}$ could have resulted from an increase in $R_{\mathrm{ap}}, R_{\mathrm{ba}}$, or $R_{s}$ (see Fig. 1). As shown in Figure $5 B$, although the increase in $R_{\text {tot }}$ (and thus $R_{t}$ as well) appeared to be monophasic, choroidal DIDS altered the ratio of apical to basal membrane resistances ( $a$ value) in 2 distinct phases. In the first phase, concordant with basal membrane hyperpolarization (Fig. 2), the $a$ value decreased while $R_{\text {tot }}$ increased, consistent with an increase in RPE basal membrane resistance. In the second phase, concordant with apical membrane depolarization, the $a$ value increased, while $R_{\text {tot }}$ continued to increase, consistent
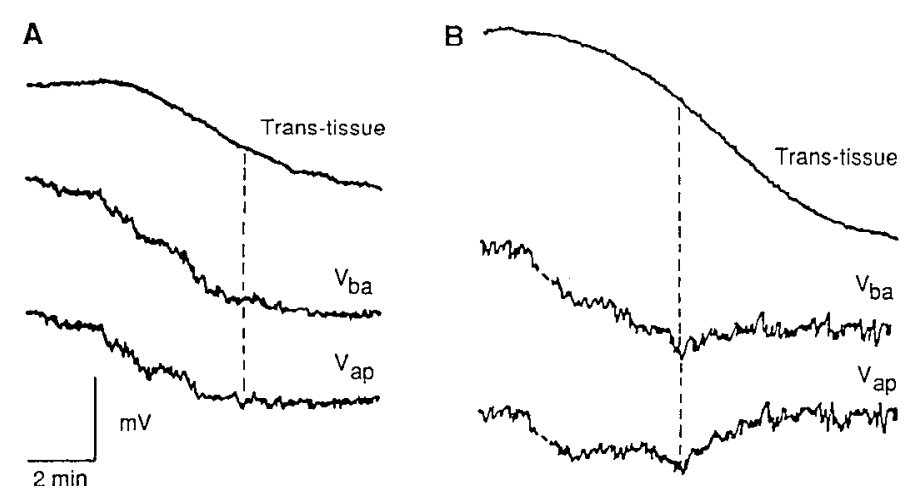

\section{DIDS}

Figure 3. Effect of choroidal DIDS perfusion on RPE membrane potentials and the TTP for $50 \mu \mathrm{M}$ DIDS $(A)$ and $100 \mu \mathrm{M}$ DIDS $(B)$. The TTP was recorded differentially between the retinal and choroidal perfusates. Simultaneously, the apical membrane potential $\left(V_{\mathrm{ap}}\right)$ was recorded differentially between the intracellular microelectrode and the retinal perfusate; the basal membrane potential $\left(V_{\mathrm{ba}}\right)$ was recorded between the microelectrode and the choroidal perfusate. Although the TTP decrease appears to be monophasic, the effect of DIDS on the RPE membrane potentials occurred in 2 distinct phases, which are demarcated by the vertical interrupted lines. The perfusate was changed to the test solution containing DIDS as indicated at the bottom by the bars. Vertical calibration: $2 \mathrm{mV}$ for $V_{\text {ap }}$ and $V_{\text {ba }}$ and $1 \mathrm{mV}$ for transtissue.
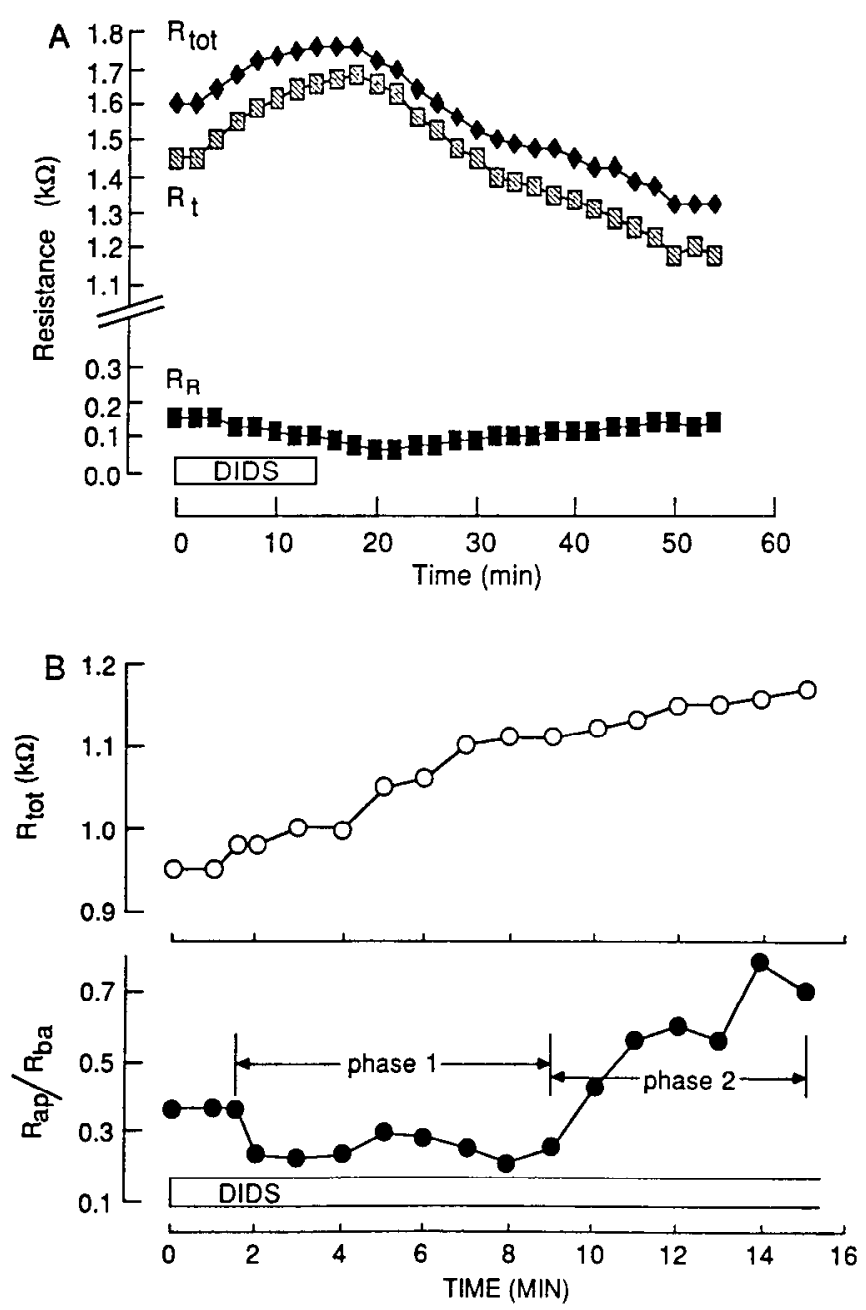

Figure 4. Effect of choroidal DIDS perfusion on resistance measurements. $A$, Change in the total tissue resistance $\left(R_{\mathrm{tol}}\right)$ and its components, the transretinal resistance, $R_{R}$, and the transepithelial, resistance, $R_{t}$ before, during, and after choroidal perfusion with $35 \mu \mathrm{M}$ DIDS. DIDS caused an increase in $R_{\mathrm{tot}}$ that was due to an increase in $R_{r}$. Note the $50 \%$ decrease in $R_{R}$. B, Effect of choroidal DIDS perfusion $(100 \mu \mathrm{M})$ on the intracellularly recorded resistance ratio $\left(R_{\mathrm{ap}} / R_{\mathrm{ba}}\right.$, or $a$ value $)$ as correlated with changes in total tissue resistance, $R_{\mathrm{tor}}$. Although the increase in $R_{1 m}$ appears to be monophasic, the effect of DIDS on the $a$ value actually occurred in 2 phases: an early phase (Phase 1) and a later phase following prolonged exposure to DIDS (Phase 2).

with an increase in RPE apical membrane resistance. In this example, the $a$ value increased in the second phase above the $a$ value before choroidal perfusion with $100 \mu \mathrm{M}$ DIDS. In other cases, the $a$ value did not increase in the second phase above its pre-DIDS value ( 3 cells: $50 \mu \mathrm{M}, n=1 ; 100 \mu \mathrm{M}, n=2$ ).

There is a second method, the intracellular recording of the c-wave of the DC ERG, which is independent of the a-value measurement and can be used to identify the origin of the DIDSinduced increase in $R_{t}$. Before considering the results of this analysis, we must first describe the effects of choroidal DIDS on the c-wave.

C-wave

A reversible decrease in c-wave amplitude was always observed during choroidal DIDS perfusion (Fig. 5). The voltage changes of the c-wave are produced by a light-evoked decrease in subretinal $\mathrm{K}^{+}$(Oakley and Green, 1976; Oakley, 1977; Steinberg 

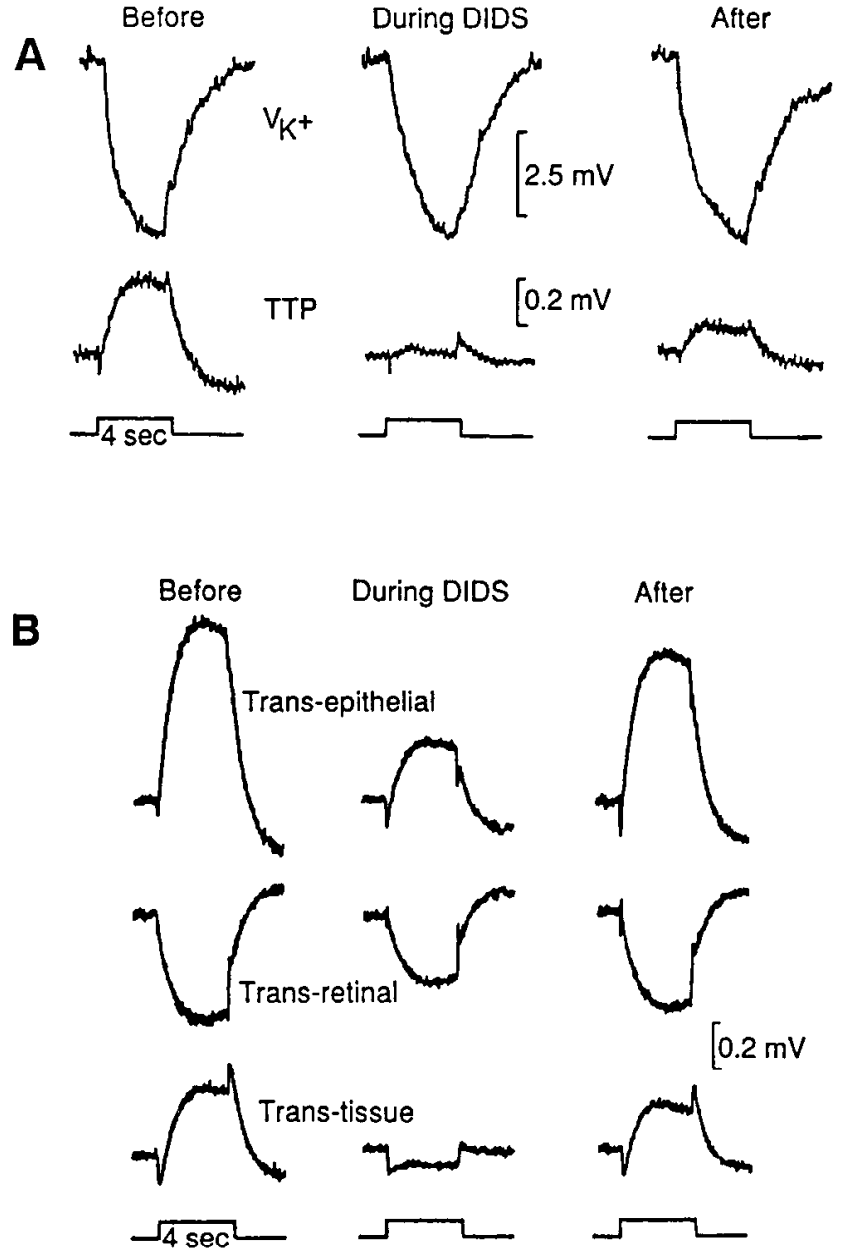

Figure 5. Choroidal DIDS perfusion and the c-wave. $A$, Light-evoked changes in subretinal potassium concentration $\left(V_{\mathrm{K}^{+}}\right)$and the transtissue $\mathrm{c}$-wave (TTP) in response to a $4 \mathrm{sec}$ stimulus $\left(6 \times 10^{-5} \mathrm{~W} / \mathrm{cm}^{2}\right)$ before, during, and after choroidal perfusion with $50 \mu \mathrm{M}$ DIDS. A $10.0 \mathrm{mV}$ change in $V_{\mathrm{K}^{+}}$corresponds to a change of approximately $2.5 \mathrm{~mm}$ in the extracellular $\mathrm{K}^{+}$level in the subretinal space, $\left[\mathrm{K}^{+}\right]_{0}$. The dark-adapted $\left[\mathrm{K}^{+}\right]$was measured to be $5.4 \mathrm{~mm}, 0.4 \mathrm{~mm}$ greater than the control perfusate, and was not changed by DIDS (not shown). $B$, Selected transepithelial (RPE c-wave) and transretinal (slow PIII) components of the TTP c-wave before, during, and after choroidal perfusion with $35 \mu \mathrm{M}$ DIDS.

et al., 1980). Figure $5 A$ illustrates the light-evoked $\mathrm{K}^{+}$decrease measured when the c-wave reduction in DIDS was maximal ("During DIDS") compared with control and recovery responses. The light-evoked $\mathrm{K}^{+}$decrease, recorded with a $\mathrm{K}^{+}$selective microelectrode in the subretinal space, was not reduced at any time by choroidal DIDS and, therefore, did not cause the $c$-wave reduction. Similar results were obtained in 3 tissues (50 $\mu \mathrm{M}$ DIDS).

The c-wave amplitude decrease and recovery paralleled in time course the decrease and recovery of the TTP, with the c-wave amplitude reaching its minimum at about the minimum of the TTP. Figure 6 shows that for all concentrations of choroidal DIDS, the maximum decrease in c-wave amplitude was well correlated with the size of the TTP (standing potential) change. These data suggest, therefore, that the mechanisms underlying the changes in the c-wave and TTP are related.

The transtissue c-wave is the sum of the negative-going potential generated in the neural retina (slow PIII) and a positive-

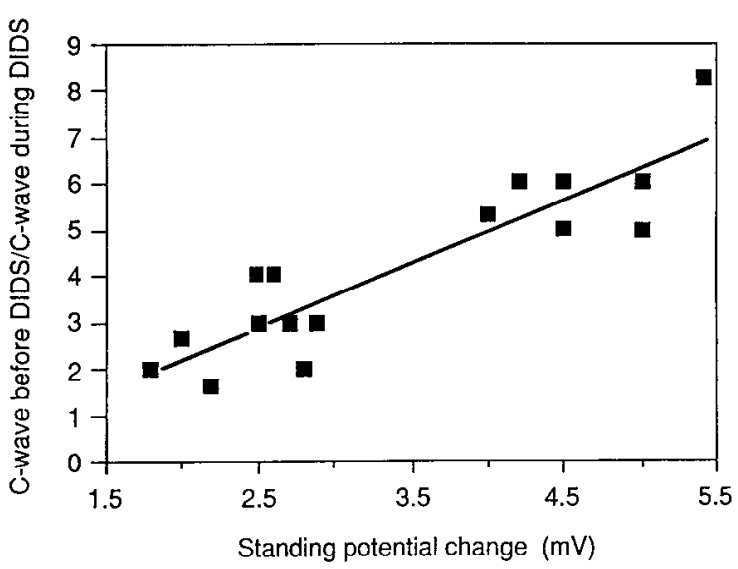

Figure 6. Maximal change in c-wave amplitude (c-wave during DIDS/ c-wave before DIDS) as a function of the maximal change in transtissue potential (standing potential) caused by DIDS. Data from choroidal perfusions with DIDS $(10-125 \mu \mathrm{M})$ in 21 chicks are shown. The line is a lincar regression with a slope of 1.39 , a $y$-intercept of 1.50 and a correlation coefficient of 0.80 .

going component from the RPE, the transepithelial or RPE c-wave (Faber, 1969; Rodieck, 1972; Linsenmeier and Steinberg, 1983). The change in c-wave amplitude could have resulted from a change in either or both of these components. The transepithelial and transretinal c-wave components can be separately recorded by positioning a microelectrode in the subretinal space. We found that the RPE c-wave became significantly smaller in amplitude while slow PIII decreased much less, ${ }^{1}$ for example, 67 versus $38 \%$ in Figure $5 B$. Since a decrease in slow PIII alone would increase the $c$-wave, the decrease in the transtissue $c$-wave must be attributed to the decrease in its RPE component.

\section{Resistance assessment: intracellular c-wave responses}

Figure 7 shows apical and basal membrane c-wave hyperpolarizations and the transtissue c-wave in response to 4 sec flashes presented before and during choroidal perfusion with $50 \mu \mathrm{M}$ DIDS. As described above, the RPE c-wave results from a hyperpolarization of the apical membrane in response to a lightevoked decrease in subretinal potassium. The apical membrane hyperpolarization is shunted to the basal membrane (across $R_{s}$, Fig. 1), so that both the apical and basal membranes hyperpolarize, and this is illustrated in the control response in Figure $7 A$ ( $V_{\text {ap }}$ does not include $V_{R}$ in this figure $\left.{ }^{2}\right)$. Note that the apical membrane hyperpolarization is larger than the basal membrane

\footnotetext{
' Effect of DIDS on the transretinal potential (Fig. 2) and slow PIII were not due to changes in subretinal $\left[\mathrm{K}^{+}\right]_{0}$. Dark-adapted subretinal $\left[\mathrm{K}^{+}\right]_{0}$ was not altered by choroidal DIDS $(50 \mu \mathrm{M}, n=3)$ and the light-evoked decrease in $\left[\mathrm{K}^{+}\right]_{0}$, which generates slow PIII (Witkovsky et al., 1975; Wen and Oakley, 1987), was not affected by DIDS (Fig $5 \mathrm{~A}$ ). At least 2 factors contribute to the decrease in slow PIII. First, a fraction of slow PIII is a voltage drop across the transretinal $\left(R_{R}\right)$ resistance produced by the RPE c-wave current (Linsenmeier and Steinberg, 1987), so that a decrease in the RPE c-wave alone will decrease slow PIII. Second, the decrease in $R_{R}$ during choroidal DIDS perfusion (Fig. $4 A$ ) will decrease slow PIII. The increase of the dark-adapted transretinal potential may represent a passive voltage drop across the transretinal resistance of the decreasing TEP.

2 With the intracellular microelectrode referenced to the retinal bath, we actually measure $\left(V_{\text {ap }}+V_{R}\right)$ (see Materials and Methods and Fig. 1). To estimate $V_{\text {ap }}$ more accurately, we subtracted the change in $V_{R}$ during illumination (slow PIII) using data from a similar experiment (controlling for DIDS concentration, maximum percent decrease in TTP c-wave, control TTP, and control c-wave amplitude). We found that our conclusions were the same whether we looked at the change in $\left(V_{\mathrm{ap}}+V_{R}\right)$ or the estimated change in $V_{\mathrm{ap}}$. We have illustrated the estimated change in $V_{\mathrm{ap}}$ in Figure 7
} 


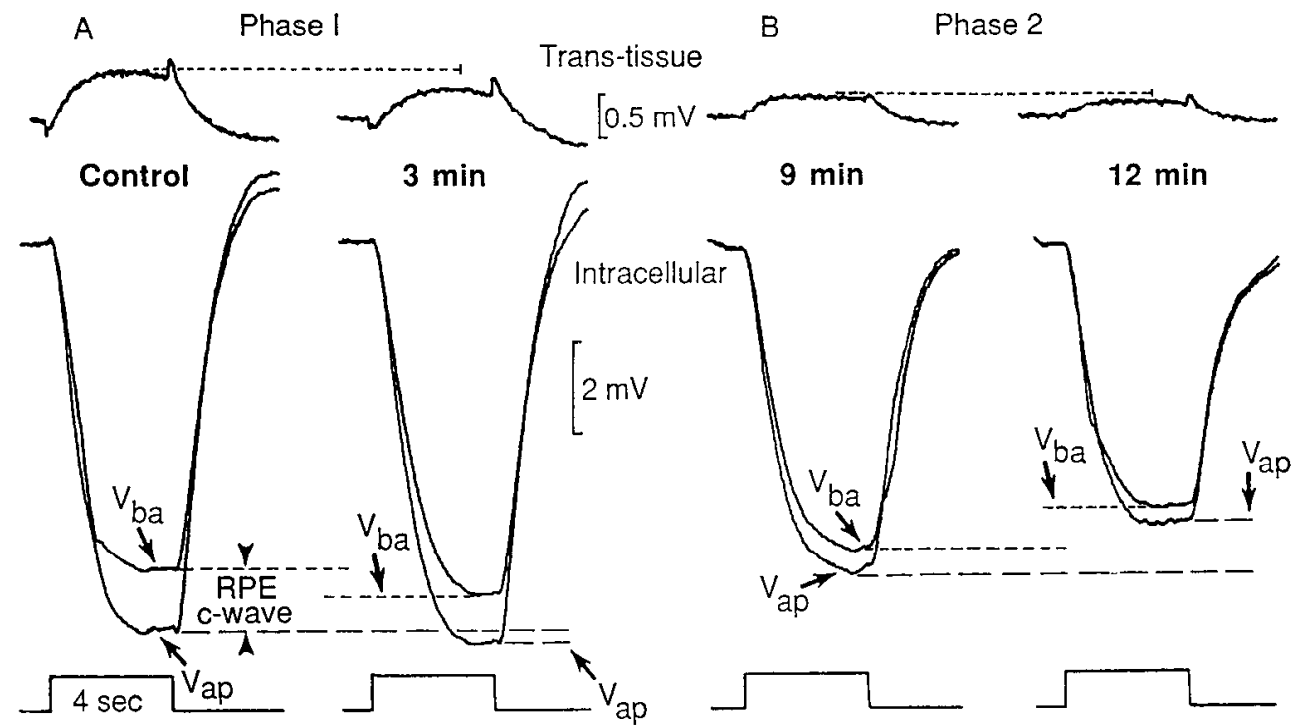

Figure 7. Effect of $50 \mu \mathrm{M}$ choroidal DIDS on the intracellularly recorded RPE c-wave as correlated with changes in the transtissue $c$-wave. The recording configuration is the same as in Figure 3 . The control response illustrates that the RPE c-wave is the difference between the apical $\left(V_{\mathrm{ap}}\right)$ and basal $\left(V_{\mathrm{ba}}\right)$ membrane hyperpolarizations in response to light. The effect of choroidal DIDS on the membrane hyperpolarizations occurred in 2 distinct phases: $(A)$ an earlier phase (Phase 1) where both apical and basal hyperpolarizations increased and $(B)$ a later phase (Phase 2) where both apical and basal hyperpolarizations decreased. Note decrease in transtissue c-wave during both phases. The times following the start of DIDS perfusion are indicated in the figure.

hyperpolarization and that the difference between these hyperpolarizations is the RPE c-wave.

The RPE c-wave hyperpolarizations also changed in 2 phases. In the first phase (Fig. $7 A$ ), concordant with the underlying basal membrane hyperpolarization (Fig. 3), the c-wave hyperpolarizations of both $V_{\text {ap }}$ and $V_{\text {ba }}$ increased, with the increase in $V_{\text {ba }}$ being larger so that a decrease in the transtissue c-wave occurred. Since the light-evoked $\mathrm{K}^{+}$decrease was unchanged by DIDS (Fig. $5 A$ ), the intracellular c-wave hyperpolarizations could have been altered by a change in $R_{\mathrm{ap}}, R_{\mathrm{ba}}$, or $R_{s}$ (see Eqs. 5 and 6). The $a$-value and $R_{t}$ measurements (Fig. $4 B$ ) pointed to an apparent increase in $R_{\mathrm{ba}}$ during phase 1 . If $R_{\mathrm{ba}}$ increased, then Equations (5) and (6) predict larger c-wave hyperpolarizations of $V_{\text {ap }}$ and $V_{\text {ba }}$, with different predictions for changes in $R_{\text {ap }}$ or $R_{s}$ (Linsenmeier and Steinberg, 1983). The larger c-wave hyperpolarizations in phase 1 of Figure 7, therefore, support the hypothesis that $R_{\mathrm{ba}}$ increased. As predicted by Equation (7), an apparent increase in $R_{\mathrm{ba}}$ alone can reduce the amplitude of the c-wave. This finding also has been reported for the effect of basal hyperosmolarity on the c-wave (Shirao and Steinberg, 1987).

In the second phase (Fig. $7 B$ ), concordant with apical membrane depolarization, the c-wave changes in both $V_{\text {ap }}$ and $V_{\text {ba }}$ were smaller, with the decrease in $V_{\mathrm{ap}}$ being greater so that $c$-wave amplitude decreased further. Resistance measurements during phase 2 (Fig. $4 B$ ) suggested that $R_{\mathrm{ap}}$ increased during this period. Consistent with this result, Equations (5) and (6) predict smaller $c$-wave hyperpolarizations when $R_{\mathrm{ap}}$ increases. Note that the apical membrane hyperpolarization became significantly smaller during the second phase (compare with control response) and by $16 \mathrm{~min}$ (not shown) had increased by $45 \%$ as compared to the control response. Similar results were observed in all 4 experiments (50 $\mu \mathrm{M}$ DIDS, $n=2 ; 100 \mu \mathrm{M}$ DIDS, $n=2$; range of maximum percent decrease in apical membrane hyperpolarization: $45-70 \%$; mean $=57.5 \%$ ). This indicates that the responsiveness of the apical membrane to a given change in $\left[\mathrm{K}^{+}\right]_{0}$ had decreased significantly. A decrease in the apical membrane potassium conductance $\left(g_{\mathrm{K}^{+}}\right)$would account for the apparent phase 2 increase in $R_{\text {ap }}$ as well as the phase 2 apical membrane depolarization (Griff et al., 1985).

\section{Intracellular chloride activity in chick $R P E$}

In other systems, DIDS has been shown to block $\mathrm{Cl}^{-}$channels (Miller and White, 1979; Nelson et al., 1984; Inoue, 1985; Kimmich and Montrose, 1985). If DIDS hyperpolarizes the RPE basal membrane and increases its resistance by blocking a $\mathrm{Cl}^{-}$ conductance, then we would predict that $a_{\mathrm{Cl}}^{\mathrm{i}}$ is above equilibrium in the RPE cell and that application of DIDS to the basal membrane should increase $a_{\mathrm{C}}^{\mathrm{i}}$. To test this possibility, we measured $a_{\mathrm{Cl}}^{\mathrm{i}}$ in chick RPE with double-barreled $\mathrm{Cl}^{-}$-selective microelectrodes.

Criteria for acceptable impalements included (1) an abrupt negative deflection of $V_{\mathrm{ap}}, V_{\mathrm{ba}}$, and $V_{\mathrm{C}}$ on penetration of the cell, (2) a stable intracellular potential for at least $30 \mathrm{sec}$, and (3) return of the electrical potential to within $2 \mathrm{mV}$ of baseline upon withdrawal of the electrode (Armstrong and Garcia-Diaz, 1980). All penetrations were made across the apical membrane. Note that our calculations of passive distribution of $\mathrm{Cl}^{-}$activity assume the same extracellular $\mathrm{Cl}^{-}$activity as the bulk solution. Our conclusions would be unaltered even if the extracellular $\mathrm{Cl}^{-}$ activity values were within $\pm 10 \mathrm{~mm}$ of the bulk solution value.

Because the calculation of $a_{C I}^{i}$ requires an accurate measurement of membrane potential, and the larger tip size of the double-barreled microelectrode might cause significant membrane damage, we first compared measurements of $V_{\mathrm{ap}}$ and $V_{\mathrm{ba}}$ made with conventional single-barreled electrodes versus similar measurements made with double-barreled $\mathrm{Cl}^{-}$-selective electrodes. For 13 cells in 9 tissues impaled with conventional microelectrodes, $V_{\text {ap }}=-70 \pm 1.8 \mathrm{mV}$ and $V_{\text {ba }}=-63 \pm 2.1 \mathrm{mV}$ (not significantly different from those recently reported; Shirao and Steinberg, 1987). For 9 cells in 4 tissues impaled with $\mathrm{Cl}^{-}$selective microelectrodes, $V_{\mathrm{ap}}=-67 \pm 4.0 \mathrm{mV}$ and $V_{\mathrm{ba}}=-60$ $\pm 3.7 \mathrm{mV}$. Though lower, these values do not differ significantly from those measured with conventional microelectrodes $(p>$ 0.4 for $V_{\mathrm{ap}}$ and $p>0.3$ for $V_{\mathrm{ba}}$ ), indicating that significant membrane damage was not a complication.

Figure $8 A$ illustrates a representative recording of $V_{\text {ap }}, V_{\text {ba }}$, and $V_{\mathrm{Cl}}$. To withdraw from the cell the electrode was retracted only several microns to prevent penetration of the neural retina, 
A.

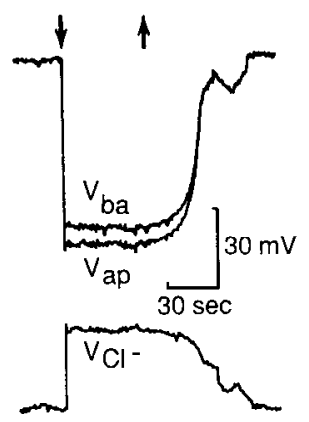

B.

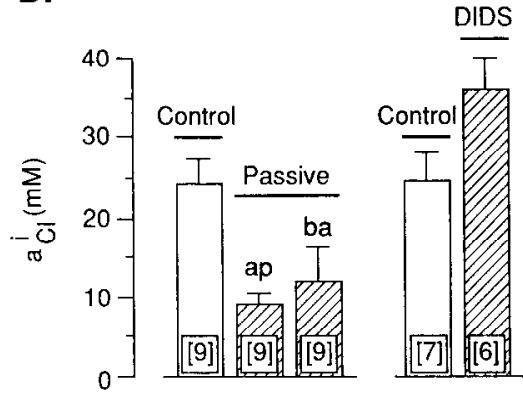

Figure 8. Intracellular chloride activity in chick RPE. $A$, Representative recording of $V_{\mathrm{ap}}, V_{\mathrm{ba}}$, and $V_{\mathrm{C}^{-}}$with a double-barreled $\mathrm{Cl}^{-}$-selective microelectrode. For this cell, $V_{\mathrm{ap}}=-73 \mathrm{mV}, V_{\mathrm{ba}}=-64 \mathrm{mV}$, and $a_{\mathrm{Cl}}^{\mathrm{i}}$ $=20.1 \mathrm{mM}$. The predicted $a_{\mathrm{cl}}^{\text {ic's }}$ 's for passive distribution of $\mathrm{Cl}^{-}$across the apical and basal membranes are 6.7 and $9.4 \mathrm{~mm}$, respectively. Arrows demarcate time of microelectrode penetration and withdrawal across the RPE apical membrane (see text for details). $B, a_{\mathrm{C}}$ is distributed above equilibrium across both the apical and basal membranes. The average $a_{C l}^{i}$ ( 9 cells in 4 tissues) was $24 \pm 2.9 \mathrm{~mm}$, about 2.6 times the $a_{c:}^{i}$ predicted for passive distribution across the apical membrane and 2.0 times the $a_{\mathrm{cl}}^{\mathrm{i}}$ predicted for passive distribution across the basal membrane. Perfusion of the basal membrane with $50 \mu \mathrm{M}$ DIDS produced a significant increase in $a_{c 1}^{\mathrm{i}}(p<0.05)$. In the presence of basal DIDS, the average $a_{C 1}^{\mathrm{i}}$ (6 cells in 2 tissues) was $36 \pm 4.1 \mathrm{~mm}$, about 1.5 times the average $a_{\mathrm{C}}$ measured in control perfusate (for 7 control cells in the 2 tissues, $a_{\mathrm{Cl}}^{\mathrm{i}}=24.5 \pm 3.5 \mathrm{~mm}$ ).

and, thus, the cell was slowly lost, as indicated by the slow recovery of potentials. For this cell, $V_{\mathrm{ap}}=-73 \mathrm{mV}, V_{\mathrm{ba}}=-64$ $\mathrm{mV}$, and $a_{\mathrm{Cl}}^{\mathrm{i}}=20.1 \mathrm{~mm}$. Using Equation (2), the predicted $a_{\mathrm{C}}^{\mathrm{i}}$ 's for passive distribution of chloride across the apical and basal membranes are 6.7 and $9.4 \mathrm{~mm}$, respectively. Thus, $\mathrm{Cl}^{-}$is actively accumulated into the chick RPE cell.

As shown in Figure $8 B$, additional measurements confirmed that $a_{\mathrm{Cl}}^{\mathrm{i}}$ was distributed above equilibrium across both the apical and basal membranes. The average $a_{\mathrm{C} 1}^{\mathrm{i}}$ (control, left; 9 cells in 4 tissues) was $24 \pm 2.9 \mathrm{~mm}$, about 2.6 times the $a_{\mathrm{Cl}}^{\mathrm{i}}$ predicted for passive distribution across the apical membrane and 2.0 times the $a_{\mathrm{Cl}}$ predicted for passive distribution across the basal membrane (cross-hatched, left). Also shown in Figure 8B, perfusion of the basal membrane with $50 \mu \mathrm{M}$ DIDS produced a significant increase in $a_{\mathrm{Cl}}^{\mathrm{i}}(p<0.05)$. In the presence of basal DIDS (12-15 min exposure), the average $a_{\mathrm{c}}^{\mathrm{i}}$ (cross-hatched, right; 6 cells in 2 tissues) was $36 \pm 4.1 \mathrm{~mm}$, about 1.5 times (or $50 \%$ more than), the average $a_{\mathrm{c}}^{\mathrm{i}}$ measured in control perfusate (control, right; for 7 control cells in the 2 tissues, $a_{\mathrm{Cl}}^{\mathrm{i}}=24.5 \pm$ $3.5 \mathrm{~mm}$ ). In 2 experiments, DIDS applied to the choroidal bath did not significantly change the apparent $a^{a}{ }_{C 1}$ outside the RPE apical membrane (not shown).

\section{Discussion}

Perfusion of the RPE basal membrane with micromolar concentrations of DIDS had significant effects on the chick RPE preparation. DIDS decreased the TTP, reduced the amplitude of the c-wave of the DC ERG and increased the total tissue resistance $\left(R_{\mathrm{tot}}\right)$. The effects of DIDS on the RPE occurred in 2 distinct phases. In the first phase, the basal membrane hyperpolarized and basal membrane resistance appeared to increase. In the second phase, which followed prolonged exposure, the apical membrane depolarized and its resistance appeared to increase.

\section{Phase 1: effect on the basal membrane}

The effects of Phase 1 are consistent with DIDS decreasing the conductance of some ion channel at the basal membrane. The ion permeating this channel must have an equilibrium potential $\left(E_{\text {ion }}\right)$ more depolarized than the resting potential of the basal membrane $\left(E_{m}\right)$ in order to hyperpolarize it when blocked. $E_{m}$ for the basal membrane was $-63 \pm 2.1 \mathrm{mV}$, and this practically eliminates a $\mathrm{K}^{+}$conductance $\left(g_{\mathrm{K}^{+}}\right)$since $E_{\mathrm{K}^{+}}$should be more hyperpolarized than $E_{m}$ and, therefore, a decrease in $g_{K^{+}}$would depolarize the membrane (Miller and Steinberg, 1977; La Cour et al., 1986). On the other hand, either a decrease in a $\mathrm{Cl}^{-}$ conductance ( $g_{\mathrm{Cl}^{-}}$where $\mathrm{Cl}^{-}$is not passively distributed) or $\mathrm{Na}^{+}$ conductance $\left(g_{\mathrm{Na}}\right)$ could hyperpolarize $E_{m}$. Since DIDS has been found to decrease $g_{\mathrm{Cl}}$ in some systems (Miller and White, 1979; Nelson et al., 1984; Inoue, 1985; Kimmich and Montrose, 1985) and has not, to our knowledge, been found to affect $g_{\mathrm{Na}^{+}}$, this analysis is consistent with basal DIDS hyperpolarizing the RPE basal membrane by reducing a $\mathrm{Cl}^{-}$conductance.

An effect of DIDS on a $g_{\mathrm{Cl}^{-}}$at the basal membrane could be direct, i.e. by blocking $\mathrm{Cl}^{-}$channels, or indirect, i.e., by blocking a $\mathrm{Cl}^{-}$uptake transporter, decreasing $\left[\mathrm{Cl}^{-}\right]_{i}$, and thereby secondarily causing a decrease in $g_{\mathrm{C}^{-}}$. The finding that DIDS increases $a_{\mathrm{CI}}^{\mathrm{i}}$ (Fig. $8 B$ ) is most consistent, therefore, with a direct effect of DIDS on a $\mathrm{Cl}^{-}$conductance at the basal membrane. There is a precedent for direct $\mathrm{Cl}^{-}$conductance blockade by DIDS in other systems (Miller and White, 1979; Nelson et al., 1984; Inoue, 1985; Kimmich and Montrose, 1985). In many preparations, however, DIDS is also known to block a number of other anion transport mechanisms (see, for example, Jentsch et al., 1986; Hughes et al., 1987; Knicklebein et al., 1985; L'Alleman et al., 1985; Sasaki et al., 1987). Thus, although our results are most easily explained by blockade of a basal membrane $g_{\mathrm{Cl}^{-}}$, other mechanisms could contribute to the DIDS effects.

Finally, that the RPE actively transports $\mathrm{Cl}^{-}$from the apical side to the basal can only be understood in terms of an apical membrane $\mathrm{Cl}^{-}$uptake mechanism and a basal membrane $\mathrm{Cl}^{-}$ permeation mechanism in frog (Miller and Steinberg, 1977), dog (Tsuboi, 1987), bovine (Edelman and Miller, 1987), and embryonic chick (Frambach and Misfeldt, 1983). Our measurements of $a_{\mathrm{Cl}}^{\mathrm{i}}$ in chick RPE (Fig. 8) indicate that $\mathrm{Cl}^{-}$is distributed above equilibrium across both the apical and basal membranes. This indicates that our preparation also actively transports $\mathrm{Cl}^{-}$, although no directionality can be inferred. Assuming that in chick net $\mathrm{Cl}^{-}$transport is also directed apical to basal, our results suggest the presence of a DIDS-sensitive chloride conductance through which $\mathrm{Cl}^{-}$, at least in part, is secreted. Edelman et al. (1988) recently found that basal DIDS blocks net $\mathrm{Cl}^{-}$transport across the frog RPE, which is also consistent with a basal membrane DIDS-sensitive $\mathrm{Cl}^{-}$secretory mechanism.

The ion-exchange resin used in our $\mathrm{Cl}^{-}$-selective electrodes has been shown to be sensitive to stilbene derivatives such as DIDS (Chao and Armstrong, 1987). The interference of extracellular DIDS in our measurements should be insignificant since RPE cells were penetrated across their apical membrane while the basal membrane was perfused with DIDS. In addition, DIDS applied to the choroidal bath did not significantly change the apparent $a_{C 1}^{\circ}$ outside the RPE apical membrane. Regarding intracellular DIDS, it and similar compounds have been characterized as "nonpenetrating probes" (Cabantchick and Roth- 
stein, 1972; Grinstein et al., 1979). Assuming, however, that any presumed permeability of the RPE membrane to DIDS is entirely passive, we can estimate the maximal interference of intracellular DIDS. ${ }^{3}$ If this interference was present in our measurements, then the apparent increase in $a_{\mathrm{cl}}^{\mathrm{i}}$ produced by choroidal perfusion with $50 \mu \mathrm{M}$ DIDS would be $20 \%$, rather than $50 \%$ (see Results). This error does not alter the conclusions we have drawn.

\section{Phase 2: effects on the apical membrane}

How might DIDS, following prolonged perfusion of the basal membrane, depolarize the apical membrane and produce an apparent increase in $R_{\mathrm{ap}}$ ? This effect may be indirect. By blocking a basal membrane transport mechanism and/or conductance, DIDS might change the intracellular activity of some ion, for example, $\mathrm{Cl}^{-}$, which would then affect a mechanism at the apical membrane, sensitive to the intracellular activity of that ion. Alternatively, DIDS could diffuse to the apical membrane and act directly on a DIDS-sensitive mcchanism. In frog RPE, a DIDS-sensitive apical membrane electrogenic $\mathrm{Na}^{+}$-dependent $\mathrm{HCO}_{3}{ }^{-}$cotransporter has recently been described (Hughes et al., 1987). Inhibition of this transporter with DIDS applied extracellularly to the apical membrane depolarized the apical membrane. We have found, as well, that application of DIDS to the apical side of the chick preparation also depolarizes the apical membrane (2-3 $\mathrm{mV} ; n=3$ ). Application of DIDS to the basal membrane first, however, did not block the apical membrane depolarization produced by apical DIDS. Furthermore, application of apical DIDS first did not block the second phase reduction of the RPE c-wave hyperpolarizations produced by basal DIDS (Gallemore and Steinberg, unpublished observations). Taken together, these results suggest that a direct effect of DIDS on the apical membrane is not the mechanism of the effects observed during the second phase.

During the second phase, apical membrane responsiveness to the light-evoked decrease in $\mathrm{K}^{+}$was reduced an average of $57.5 \%$. A reduction in $g_{\mathrm{K}^{+}}$at the apical membrane would depolarize that membrane and increase its resistance (Griff et al., 1985). These results suggest that prolonged exposure of the basal membrane to DIDS can reduce the potassium conductance of the apical membrane. If basal DIDS decreases apical $g_{\mathrm{K}^{+}}$, then this effect would most likely be indirect since, to our knowledge, DIDS has not been found to decrease directly a $g_{\mathrm{K}^{+}}$in any system studied. ${ }^{4}$ Recently, the RPE apical membrane $g_{\mathrm{K}}$, was found to be $\mathrm{pH}$ sensitive (Joseph and Miller, 1986; Keller et al., 1986). Since $\left[\mathrm{Cl}^{-}\right]_{\mathrm{i}}$ is involved in the regulation of intracellular $\mathrm{pH}$ (for a review, see Roos and Boron, 1981), basal DIDS may affect a $\mathrm{pH}$-sensitive apical membrane potassium conductance by its effect on intracellular $\mathrm{Cl}^{-}$activity.

In sum, we have presented evidence in support of a DIDSinhibitable basal membrane $\mathrm{Cl}^{-}$conductance. With prolonged exposure to basal DIDS an effect on the apical membrane was

\footnotetext{
${ }^{3}$ Given a mean RPE basal membrane potential of $-63 \mathrm{mV}$, for an extracellular DIDS concentration of $50 \mu \mathrm{M}$, the equilibrium intracellular concentration of DIDS (calculated from the Nernst equation) cannot be more than $20 \%$ of this, or $10 \mu \mathrm{M}$ (DIDS has 2 negative charges). Given a maximum electrode selectivity of $\mathrm{Cl}^{-}$: DIDS of 1:1000, and an activity coefficient of 0.75 for DIDS, this would cause an increase of $7.5 \mathrm{~mm}$ in the apparent $a_{\mathrm{Cl}}^{\mathrm{i}}$.

4 Inoue (1986), however, found that in the squid giant axon, DIDS increased a potassium conductance. In addition, Biagi (1986) demonstrated that the stilbene derivative SITS had secondary effects on a $g_{k}$. in proximal tubule. In this case, $g_{\mathrm{K}}$. increased as well.
}

observed that appears to involve the reduction of a $\mathrm{K}^{+}$conductance.

\section{References}

Armstrong, W. McD., and J. F. Garcia-Diaz (1980) Ion-selective microelectrodes: Theory and technique. Fed. Proc. 39: 2851-2859.

Baumgarten, C. M. (1981) An improved liquid ion exchange for chloride selective microelectrodes. Am. J. Physiol. 24I: C258-C263.

Biagi, B. A. (1986) Effects of the anion transport inhibitor, SITS, on the proximal tubule of the rabbit perfused in vitro. J. Membr. Biol. 88: 25-31.

Cabantchik, Z. I., and A. A. Rothstein (1972) The nature of the membrane sites controlling anion permeability of human red blood cells as determined by studies with disulfonic stilbene derivatives. J. Membr. Biol. 10: 311-330.

Chao, A. C., and W. McD. Armstrong (1987) $\mathrm{Cl}^{-}$-selective microelectrodes: Sensitivity to anionic $\mathrm{Cl}^{-}$transport inhibitors. Am. J. Physiol. 253: C343-C357.

Djamgoz, M. B. A., and J. Dawson (1986) Procedures for manufacturing double-barreled ion-selective microelectrodes employing liquid sensors. J. Biochem. Biophys. Methods 13: 9-21.

Edelman, J., and S. S. Miller (1987) Active ion transport across the bovine retinal pigment epithelium (RPE). Invest. Ophthalmol. Vis. Sci. (ARVO Abstr.) 28: 382.

Edelman, J. L., S. S. Miller, and B. A. Hughes (1988) Regulation of chloride transport by frog retinal pigment epithelium. FASEB J. 2: A1722 (abstract).

Faber, D. S. (1969) Analysis of the Slow Transretinal Potentials in Response to Light. Ph.D. dissertation, State Univ. of New York, Buffalo, NY.

Frambach, D. A., and D. S. Misfeldt (1983) Furosemide-sensitive Cl transport in embryonic chicken retinal pigment epithelium. Am. J. Physiol. 244: F679-F685.

Gallemore, R. P., and R. H. Steinberg (1987) Effects of the putative anion transport inhibitor DIDS on the RPE basal membrane and the c-wave. Invest. Ophthalmol. Vis. Sci. (ARVO Abstr.) 28: 382.

Gallemore, R. P., and R. H. Steinberg (1988) Evidence for a $\mathrm{Cl}^{-}$ conductance in chick RPE that may contribute to responses originating at the basal membrane. Soc. Neurosci. Abstr. 14:357.

Gallemore, R. P., and R. H. Steinberg (1989) Effects of DIDS on the chick retinal pigment epithelium. II. Mechanism of the light peak and other responses originating at the basal membrane. J. Neurosci. 9: 1977-1984.

Gallemore, R. P., E. R. Griff, and H. R. Steinberg (1988) Evidence in support of a photoreceptoral origin for the "light-peak substance." Invest. Ophthalmol. Vis. Sci. 29: 566-571.

Griff, E. R., and R. H. Steinberg (1982) Origin of the light peak: In vitro study of Gekko gekko. J. Physiol. (Lond.) 331: 637-652.

Griff, E. R., Y. Shirao, and R. H. Steinberg (1985) $\mathrm{Ba}^{2+}$ unmasks $\mathrm{K}^{+}$ modulation of the $\mathrm{Na}^{+}-\mathrm{K}^{+}$pump in the frog pigment epithelium. J. Gen. Physiol. 86: 853-876.

Grinstein, S., S. L. McCulloch, and A. Rothstein (1979) Transmembrane effects of irreversible inhibitors of anion transport in red blood cells: Evidence for mobile transport sites. J. Gen. Physiol. 73: 493514.

Hughes, B., S. S. Miller, and T. E. Machen (1984) Effects of cyclic AMP on fluid absorption and ion transport across frog retinal pigment epithelium. Measurements in the open circuit state. J. Gen. Physiol. 83: 875-899.

Hughes, B., S. S. Miller, J. Adorante, and S. Bialek (1987) Electrogenic Na-dependent $\mathrm{HCO}_{3}$ transport in the apical membrane of the frog retinal pigment epithelium. Invest. Ophthalmol. Vis. Sci. (ARVO Abstr.) 28: 382 .

Inoue, I. (1985) Voltage-dependent chloride conductance in the squid giant axon membrane and its blockage by some disulfonic stilbene derivatives. J. Gen. Physiol. 85: 519-538.

Inoue, I. (1986) Modification of $\mathrm{K}$ conductance of the squid giant axon membrane by SITS. J. Gen. Physiol. 88: 507-520.

Jentsch, T. J., I. Janicke, D. Sorgenfrei, S. K. Keller, and M. Weiderholt (1986) The regulation of in tracellular $\mathrm{pH}$ in monkey kidney epithelial cells (BS-1). The roles of $\mathrm{Na}^{+} / \mathrm{K}^{+}$antiport, $\mathrm{Na}^{+}-\mathrm{HCO}_{3}{ }^{-}$symport and $\mathrm{Cl}^{-} / \mathrm{HCO}_{3}{ }^{-}$exchange. J. Biol. Chem. 261: 12120-12127.

Joseph, D., and S. Miller (1986) pH dependence of apical membrane 
$\mathrm{K}$ channels in the bovine retinal pigment epithelium. Invest. Ophthalmol. Vis. Sci. (ARVO Abstr.) 27: 262.

Keller, S. V., T. J. Jentsch, M. Koch, and M. Wiederholt (1986) Interactions of $\mathrm{pH}$ and $\mathrm{K}^{+}$conductance in cultured bovine retinal pigment epithelial cells. Am. J. Physiol. 250: C124-C137.

Kikawada, N. (1968) Variations in the corneo-retinal standing potential of the vertebrate eye during light and dark adaptation. Jpn. J. Physiol. 18: 687-702.

Kimmich, G. A., and M. Montrose (1985) A SITS sensitive $\mathrm{Cl}$ conductance pathway in chick intestinal cells. Fed. Proc. 44: 1743.

Knicklebein, R. G., P. S. Aronson, and J. W. Dobbins (1985) Substrate and inhibitor specificity of anion exchangers on the brush border membrane of rabbit ileum. J. Membr. Biol. 88: 199-204.

Koryta, J., and K. Stulik (1983) Ion-Selective Electrodes, Cambridge U. P., Cambridge, UK.

La Cour, M., H. Lund-Anderson, and T. Zeuthen (1986) Potassium transport of the frog retinal pigment epithelium: Autoregualtion of potassium activity in the subretinal space. J. Physiol. (Lond.) 375: $461-479$.

L'Alleman, G., S. Paris, and J. Pouysségur (1985) Role of $\mathrm{Na}^{+}-\mathrm{de}-$ pendent $\mathrm{Cl}^{-} / \mathrm{HCO}_{3}{ }^{-}$exchange in regulation of intracellular $\mathrm{pH}$ in fibroblasts. J. Biol. Chem. 260: 4877-4883.

Linsenmeier, R. A., and R. H. Steinberg (1983) A light-evoked interaction of apical and basal membranes of retinal pigment epithelium: c-wave and light peak. J. Neurophysiol. 50: 136-147.

Linsenmeier, R. A., and R. H. Steinberg (1984) Effects of hypoxia on potassium homeostasis and pigment epithelial cells in the cat retina. J. Gen. Physiol. 84: 945-970.

Linsenmeier, R. A., and R. H. Steinberg (1987) Mechanisms of azide induced increases in the $c$-wave and standing potential of the intact cat eye. Vision Res. 27: 1-8.

Martins-Ferreira, H., and G. Oliveira Castro (1971) Spreading depression in isolated chick retina. Vision Res. Suppl. 3: 171-174.

Miller, M. M., and C. White (1979) A voltage-gated anion channel from the electric organ of Torpedo californica. J. Biol. Chem. 254: 10161-10166.

Miller, S. S., and D. Farber (1984) Cyclic AMP modulation of ion transport across frog retinal pigment epithelium. Measuremen's in the short-circuit state. J. Gen. Physiol. 83: 853-874.
Miller, S. S., and R. H. Steinberg (1977) Passive ionic properties of frog retinal pigment epithelium. J. Membr. Biol. 36: 337-372.

Nelson, D. J., J. M. Tang, and L. G. Palmer (1984) Single-channel recordings of apical membrane chloride conductance in A6 epithelial cells. J. Membr. Biol. 80: 81-89.

Oakley, B., II (1977) Potassium and the photoreceptor dependent pigment epithelial hyperpolarization. J. Gen. Physiol. 70: 405-425.

Oakley, B., II, and D. G. Green (1976) Correlation of light-induced changes in retinal extracellular potassium concentration with the $c$-wave of the electroretinogram. J. Neurophysiol. 39: 1117-1133.

Rodieck, R. W. (1972) Components of the electroretinogram-A reappraisal. Vision Res. 12: 773-780.

Roos, A., and W. F. Boron (1981) Intracellular pH. Physiol. Rev. 61: 296-434.

Saito, Y., T. Ozawa, H. Hayashi, and A. Nishiyama (1987) The effect of acetylcholine on chloride transport across the mouse lacrimal gland acinar cell membranes. Pfluegers Arch. 409: 280-288.

Sasaki, S., S. Shiagi, N. Yoshiyama, and J. Takeuchi (1987) Mechanism of bicarbonate exit across basolateral membrane of rapbit proximal straight tubule. Am. J. Physiol. 252: F11-F18.

Shirao, Y., and R. H. Steinberg (1987) Mechanisms of effects of small hyperosmotic gradients on the chick RPE. Invest. Ophthalmol. Vis. Sci. 28: 2015-2025.

Steinberg, R. H., B. Oakley II, and G. Niemeyer (1980) Light-evoked changes in $\left[\mathrm{K}^{+}\right]_{\mathrm{o}}$ in retina of intact cat eye. J. Neurophysiol. 44: 897921.

Steinberg, R. H., R. A. Linsenmeier, and E. R. Griff (1985) Reginal pigment epithelial cell contributions to the electrooculogram. Progress in Retinal Research, Vol. 4, N. Osborne and G. Chader, eds., pp. 3366, Pergamon, New York.

Tsuboi, S. (1987) Measurement of the volume flow and hydraulic conductivity across the isolated dog retinal pigment epithelium. Invest. Ophthalmol. Vis. Sci. 28: 1776-1782.

Wen, R., and B. Oakley II (1987) Müller cell involvement in electroretinogram generation and $\mathrm{pH}$ regulation in the vertebrate retina. Soc. Neurosci. Abst. 13: 1049.

Witkovsky, P., F. E. Dudek, and H. Ripps (1975) Slow PIII component of the carp electroretinogram. J. Gen. Physiol. 65: 119-135. 